\title{
Antioxidant Capacity and Phenolics of Spray Dried Arenga pinnata Juice Powder
}

\author{
Abdurrahman Adeleye Badmus, Yus Aniza Yusof, Nyuk Ling Chin and Norashikin Abd Aziz \\ Department of Process and Food Engineering, Faculty of Engineering, Universiti Putra Malaysia (UPM), Serdang 43400, Selangor, \\ Malaysia
}

\begin{abstract}
The ferric reducing antioxidant power, total phenolic content, radical scavenging activity, amino acid content and sugar content of spray dried Arenga pinnata juice powder were evaluated to determine the quality of spray dried powder obtained by spray drying of fresh Arenga pinnata juice at inlet temperature of $130{ }^{\circ} \mathrm{C}$, feed flow rate of $350 \mathrm{~mL} / \mathrm{h}$, outlet temperature of $70{ }^{\circ} \mathrm{C}$ and maltodextrin $10 \mathrm{DE}$ addition at $20 \%$. Powder obtained has a total phenolic compounds content of $5.82 \mathrm{mg} / 100 \mathrm{~g}$ of gallic acid equivalent (GAE) and antioxidant potential identified by free radical scavenging activity $\left(\mathrm{IC}_{50}\right)$ was $0.6 \mu \mathrm{mol} / \mathrm{g}$. The total sugar content of Arenga pinnata powder resulted in $30.14 \%$. The analysis of free amino acids depicted the presence of lysine, glutamic acid, aspartic acid and alanine at higher levels. The nutritional profile of the powder is vital in delivering beneficial properties when reconstituted into juice.
\end{abstract}

Key words: Arenga pinnata, antioxidant activity, phenolic compounds.

\section{Introduction}

Arenga pinnata is the most versatile palm specie, because almost all parts of the tree can be used with the sap being the most important product $[1,2]$. Palm sap is consumed fresh as juice in local communities in Southeast Asia, because it is believed to be highly nutritious and a good antioxidant.

Antioxidants are molecules that inhibit the oxidation of other molecules that can produce free radicals leading to chain reactions that may damage cells [3]. Generally, fresh sap juice obtained from Arenga pinnata tree is sweet, oyster white colour and translucent with nearly neutral $\mathrm{pH}$. The quality of sap juice is affected during storage by the $\mathrm{pH}$ of sap and reducing sugar content. Microorganisms use sugars in the sap as an energy source to produce organic acids.

Spray drying is a method of producing a dry powder from a liquid or slurry by rapidly drying with a hot gas in a single processing step, which can be

Corresponding author: Yus Aniza Yusof, Ph.D., research field: food process engineering. advantageous for profit maximization and process simplification $[4,5]$. It is useful as a method to transfer those molecules responsible for sensory and or biofunctional properties to a solid phase, which will be able to enhance their stability and control their release in food matrices [6]. The advantages of a dried powder over conventional liquid forms of juice are lower storage costs, a higher concentration and the stability of active substances. Spray dried Juice powder offers several advantages to protect sensitive food components against unfavourable ambient condition, mask or preserve flavours and aromas, reduce volatility and reactivity and also provide additional attractiveness for the merchandising of food products. Spray drying has been widely utilized for the commercial production of fruit juice powders. Thus, the present study was carried out to assess the antioxidant capacity of spray dried Arenga pinnata powder with emphasis on ferric reducing antioxidant power, total phenolic content, radical scavenging activity, amino acid content and sugar content of spray dried Arenga pinnata juice powder. 


\section{Materials and Methods}

\subsection{Juice Preparation}

Samples were prepared with concentrated sugar palm (Arenga pinnata) juice. Fresh sugar palm juice tapped from sugar palm tree (Arenga pinnata) was collected locally at Serdang, Malaysia. Food grade maltodextrin $10 \mathrm{DE}$ was sourced locally and added as drying aids.

\subsection{Obtaining Powders by Spray Drying}

Spray drying was carried out with a spray dryer lab plant SD-05 (West Yorkshire, UK), comprising of spray chamber of $1,050 \mathrm{~mm} \times 620 \mathrm{~mm} \times 500 \mathrm{~mm}$ and $0.5 \mathrm{~mm}$ standard diameter nozzle with co-current flow. The spray drying was conducted at inlet air temperature $130{ }^{\circ} \mathrm{C}$, pump speed $350 \mathrm{~mL} / \mathrm{h}$, outlet air temperature $70{ }^{\circ} \mathrm{C}$ and maltodextrin addition at $20 \%$. Ambient temperature was maintained at $27{ }^{\circ} \mathrm{C}$ and relative humidity of $56 \% \pm 1 \%$. The dryer was washed with water at the desired parameter setting for $10 \mathrm{~min}$ before and after the spray drying process. Spray dried powders were collected in clean container with known weight and kept inside the desiccators until it cooled down. Powders were then weighed, sealed in bottle and stored at $4{ }^{\circ} \mathrm{C}$ for analysis.

\subsection{Ferric Reducing Antioxidant Power (FRAP) Assay}

FRAP assay was performed according to method of Buasod [7]. $500 \mu \mathrm{L}$ of the samples were added to 1.25 $\mathrm{mL}$ of phosphate buffer and $1.25 \mathrm{~mL}$ of potassium ferricyanide $(1 \%)$. The mixtures were incubated at $50{ }^{\circ} \mathrm{C}$ for $20 \mathrm{~min}$ and then $1.25 \mathrm{~mL}$ of trichloroacetic acid solution (10\%) was added. Then, the mixture was combined with $1.25 \mathrm{~mL}$ of deionized water and 0.25 $\mathrm{mL}$ of $\mathrm{FeCl}_{3}$ (1\%). The ferric-tripyridyltriazine $\left(\mathrm{Fe}^{3+}\right.$-TPTZ) complex having an intense blue colour was measured by reading the absorbance at $595 \mathrm{~nm}$. Results were expressed as $\mu \mathrm{mol}$ of gallic acid per $\mathrm{g}$ of sample.

\subsection{2,2-Diphenyl-1-Picrylhydrazyl (DPPH) Radical Scavenging Activity}

DPPH radical scavenging activities were determined on the base of a method developed by Mansouri et al. [8]. A sample (1.5 mL) was added to $1.5 \mathrm{~mL}$ of $0.15 \mathrm{mM}$ DPPH in methanol. The mixture was vortexed and allowed to stand at room temperature at $25 \pm 2{ }^{\circ} \mathrm{C}$ in dark light for $60 \mathrm{~min}$. The absorbance of the resulting solution was measured at $517 \mathrm{~nm}$ using a UV-visible spectrophotometer (Ultrospec 3100 Amershan Biosciences). The blank was prepared in the same manner, except the distilled water was used instead of sample. Percentage of DPPH radical inhibition was calculated according to $\mathrm{Eq}(1)$ :

$$
\% \text { DPPH inhibition }=\left[\frac{\left(A_{c}-A_{S}\right)}{A_{c}}\right] \times 100
$$

where, $A_{S}$ is the absorbance of sample solution and $A_{c}$ is the absorbance of the DPPH solution.

\subsection{Determination of Total Phenolics Content}

Total phenolics content of the extracts was determined according to the method developed by Singleton and Rossi [9]. In brief, $100 \mu \mathrm{L}$ aliquot of the extract was added to $2 \mathrm{~mL}$ of $20 \mathrm{~g} / \mathrm{L} \mathrm{Na}_{2} \mathrm{CO}_{3}$ solution. After $2 \mathrm{~min}, 100 \mu \mathrm{L}$ of $50 \%$ Folin-Ciocalteu reagent was added, and the mixture was allowed to stand for 2 $\mathrm{h}$ at $25^{\circ} \mathrm{C}$. The absorbance was measured at $750 \mathrm{~nm}$ using a spectrophotometer (UV 1601, Shimadzu Co., Ltd., Kyoto, Japan). The total phenolics content was determined using the standard gallic acid calibration curve and the results were expressed as milligram gallic acid equivalents per gram sample dry weight (mg GAE/g DW).

\subsection{Determination of Type and Concentration of Sugar}

The type and concentration of sugar were determined using high performance liquid chromatography (HPLC) (Shimadzu, CR6A Chromatopac) with a $\mathrm{NH}_{2}$ HPLC column (4.6 $\mathrm{mm} \times$ 
$250 \mathrm{~mm}, 5 \mathrm{~m}$ particle size, Lichrosorb $\mathrm{NH}_{2}$ Merck, Germany, thermostated at $30{ }^{\circ} \mathrm{C}$ ), and a refractive index (RI) detector was used for detection of sugar peaks. The mobile phase used was the solution of acetonitrile and water (85:15), pumped at a flow rate of $1.5 \mathrm{~mL} / \mathrm{min}$ and injection volume $20 \mu \mathrm{L}$. The samples were prepared by making appropriate dilutions with distilled water. All sample solutions were passed through a $0.45 \mu \mathrm{m}$ syringe filter (nylon) to remove particulates prior to HPLC analysis. D-glucose, D-fructose and sucrose were used as external standards.

\subsection{Amino Acid Determination}

The amino acids were separated by reverse-phase HPLC column (waters Milford, MA) controlled by a breeze system (waters). The hydrolysates were injected in a pre-column derivatized with 6-aminoquinolyl-N-hydroxysuccinimidyl carbamate (ACCQ) to determine primary amino acids. The separation of amino acids was performed on a waters AccQ-Tag $(3.9 \mathrm{~mm} \times 150 \mathrm{~mm})$. The mobile phases used were solvent A (1: 10 ratio AccQ-Tag Eluent A concentrate commercial to deionized water) and solvent B was $60 \%(\mathrm{v} / \mathrm{v})$ acetonitrile solutions. The injection volume was $100 \mu \mathrm{L}$ and a flow rate of 1 $\mathrm{mL} / \mathrm{min}$ was used. For the determination of tryptophan, the hydrolysates were separated on a waters $\mathrm{C}_{18}$ column $(3.9 \mathrm{~mm} \times 300 \mathrm{~mm}$ ) using the same mobile phase. The fluorescent detector was adjusted at excitation wavelength of $250 \mathrm{~nm}$ and emission wavelength of $395 \mathrm{~nm}$. All reagents used were HPLC grade. Amino acids were quantified by comparing peak area of the samples with those of the internal standard, AABA.

\section{Results and Discussion}

In general, antioxidant activity is derived from phenolic compounds and/or vitamins [10]. Arenga pinnata sap juice is believed to have phenolic content which can act as antioxidant. The potency of the antioxidant property could be affected by the spray drying process. In this study, the widely-used DPPH inhibition and FRAP assays have been applied and data obtained are as reported in Table 1.

The total phenolic content in Arenga pinnata juice powder refers to the total amount of phenolic compounds present in the powder after spray drying. The phenolic compounds were found to contain 5.82 $\mathrm{mg}$ of GAE/100 $\mathrm{g}$ of total phenolic. Naknean and Meenune [11] studied the characteristics and antioxidant activity of palm sugar syrup produced by thermally heating the palm sap. The phenolic content of palm sugar (Borrasus flabellifer Linn.) samples obtained after heating fresh sap was found to range from $1.35 \mathrm{mg}$ GAE to $2.21 \mathrm{mg}$ GAE/100 g of sample. Naturally fresh palm sap contains phenolic compounds. Aeimsard et al. [12] studied the effect of vacuum drying on total phenolic compounds, antioxidant activities and physical properties of palm sugar. The total phenolic content was $214 \mathrm{mg}$ GAE/100 g dry weight. Hence, spray drying is preferred for the stability of phenolic compounds. Increase of total phenolic content may enhance the action of radical scavenging activity. The antioxidant activity comes from the hydroxyl group of polyphenols that can be quenched by DPPH radicals at immediate stages of oxidation or the formation of new compounds with higher antioxidant activity.

Phenolic content is interrelated closely to the DPPH radical scavenging activity. The DPPH inhibition of Arenga pinnata juice powder range from $26.81 \%$ to $28.74 \%$ inhibition. Naknean and Meenune [11] reported the DPPH radical scavenging activity of thermally heated palm sap syrup ranged from 13.27 $\mu \mathrm{mol}$ trolox equivalent (TE) to $18.49 \mu \mathrm{mol} \mathrm{TE} / \mathrm{g}$ of sample. While, Aeimsard et al. [12] reported the DPPH inhibition at $43.33 \%$. The antioxidant activity of phenolic compounds is clearly related to free radical scavenging and hydrogen-donation ability. The ferric reducing antioxidant power varied between 0.539 $\mu \mathrm{mol} / \mathrm{g}$ and $0.550 \mu \mathrm{mol} / \mathrm{g}$ of powder. Aeimsard et al. 
Table 1 Antioxidant capacity of spray dried Arenga pinnata powder.

\begin{tabular}{lll}
\hline $\begin{array}{l}\text { Total phenolic content } \\
\text { GAE }(\mathrm{mg} / 100 \mathrm{~g})\end{array}$ & $\begin{array}{l}\text { DPPH } \\
(\% \text { inhibition })\end{array}$ & $\begin{array}{l}\text { FRAP value } \\
(\mu \mathrm{mol} / \mathrm{g})\end{array}$ \\
\hline $5.82-5.83$ & $26.81-28.74$ & $0.539-0.550$ \\
\hline
\end{tabular}

Table 2 Sugar profile of Arenga pinnata powder.

\begin{tabular}{llll}
\hline Fructose $(\mathrm{g} / 100 \mathrm{~g})$ & Glucose $(\mathrm{g} / 100 \mathrm{~g})$ & Sucrose $(\mathrm{g} / 100 \mathrm{~g})$ & Maltose $(\mathrm{g} / 100 \mathrm{~g})$ \\
\hline $\mathrm{ND}(<0.001)$ & $\mathrm{ND}(<0.001)$ & $29.16-31.11$ & $\mathrm{ND}(<0.001)$ \\
\hline
\end{tabular}

ND: not detected.

Table 3 Amino acid profile of Arenga pinnata powder.

\begin{tabular}{lll}
\hline No. & Amino acid & $\mathrm{g} / 100 \mathrm{~g}$ \\
\hline 1 & Hydroxyproline & $0.004-0.010$ \\
2 & Aspartic acid & $0.102-0.096$ \\
3 & Serine & $0.068-0.071$ \\
4 & Glutamic acid & $0.242-0.245$ \\
5 & Glycine & $0.050-0.051$ \\
6 & Histidine & $0.000-0.000$ \\
7 & Arginine & $0.048-0.055$ \\
8 & Threonine & $0.031-0.032$ \\
9 & Alanine & $0.093-0.095$ \\
10 & Proline & $0.025-0.029$ \\
11 & Thyrosine & $0.005-0.028$ \\
12 & Valine & $0.022-0.029$ \\
13 & Methionine & $0.014-0.041$ \\
14 & Lysine & $0.218-0.224$ \\
15 & Isoleusine & $0.018-0.021$ \\
16 & Leusine & $0.012-0.015$ \\
17 & Phenylalanine & $0.008-0.008$ \\
\hline
\end{tabular}

[12] similarly reported that ferric reducing antioxidant power was at $1.11 \mu \mathrm{mol} / \mathrm{g}$ for vacuum dried palm sugar.

The sugar profile of Arenga pinnata powder was ascertained. Quantities of glucose, fructose, maltose and sucrose were determined and data are compiled in Table 2. The major saccharide was sucrose ranging from $29.16 \mathrm{~g} / 100 \mathrm{~g}$ to $31.11 \mathrm{~g} / 100 \mathrm{~g}$ of sample. Exceptionally, high amounts of sucrose were found, but glucose, fructose and maltose levels were extremely low and not detected. Similar results were reported by Naknean and Meenune [11] in the characterisation of palm sugar syrup obtained by heating. The most abundant sugar found in palm sugar syrup was sucrose $(59.15 \%)$, glucose $(4.01 \%)$ and fructose $(4.44 \%)$. It is obvious that sucrose was in abundance.
Relative quantities of free amino acids in Arenga pinnata powder determined by Accq-Tags waters method are compiled in Table 3. Varying kind and quantities of free amino acid was detected in the Arenga pinnata powder. Exceptionally, high amounts of lysine, glutamic acid, aspartic acid and alanine were found in the Arenga pinnata powder. Others found in reasonable amounts are methionine, threonine, arginine, serine and glycine. Others found negligible amounts are leusine, isoleusine, valine, proline, thyrosine and hydroxyproline. Similar results were reported by Pätzold and Brückner [13] in maple syrup, palm honey, grape syrup and sugar cane syrup.

\section{Conclusions and Recommendations}

Data have shown the high levels of polyphenols and presence of antioxidant capabilities from the phenolic contents, antioxidant capacity and free radical scavenging activity measured, sugar content and amino acid. Hence, Arenga pinnata juice powder can be reconstituted into a nutritious juice with beneficial bioactive compounds.

\section{References}

[1] Siregar, J. P. 2005. "Tensile and Flexural Properties of Arenga pinnata Filament (Ijuk Filament) Reinforced Epoxy Composites." M.Sc. thesis, Universiti Putra Malaysia (UPM).

[2] Sanyang, M. L., Sapuan, S. M., Jawaid, M., Ishak, M. R., and Sahari, J. 2016. "Effect of Sugar Palm-Derived Cellulose Reinforcement on the Mechanical and Water Barrier Properties of Sugar Palm Starch Biocomposite Films." BioResources 11 (2): 4134-45.

[3] Rice-Evans, C. A., Miller, N. J., and Paganga, G. 1996. "Structure Antioxidant Activity Relationships of Flavonoids and Phenolic Acids." Free Radic Biol Med. 
20 (7): 933-56.

[4] Yousefi, S., Emam-Djomeh, Z., and Mousavi, S. M. 2011. "Effect of Carrier Type and Spray Drying on the Physicochemical Properties of Powdered and Reconstituted Pomegranate Juice (Punica granatum L.)." J. Food Sci. Technol. 48 (6): 677-84.

[5] Sagar, V. R., and Suresh-Kumar, P. 2010. "Recent Advances in Drying and Dehydration of Fruits and Vegetables: A Review.” J. Food Sci. Technol. 47 (1): 15-26.

[6] Verma, A., and Singh, S. V. 2015. "Spray Drying of Fruit and Vegetable Juices-A Review." Crit. Rev. Food Sci. Nutr. 55 (5): 701-19.

[7] Buasod, P. 2006. "Antioxidant Capacity Test of Tea Beverages by Cyclic Voltammetry." M.Sc. thesis, Silpakorn University, Nakhon Pathom, Thailand.

[8] Mansouri, A., Embarek, G., Kokkalou, E., and Kefalas, P. 2005. "Phenolic Profile and Antioxidant Activity of the Algerian Ripe Date Palm Fruit (Phoenix dactylifera).” Food Chemistry 89 (3): 411-20.
[9] Singleton, V. L., and Rossi, J. A. 1965. "Colorimetry of Total Phenolics with Phosphomolybdic-Phosphotungstic Acid Reagents." American J. Enol. Vitic. 16: 144-58.

[10] Kim, D. O., Jeong, S. W., and Lee, C. Y. 2003. "Antioxidant Capacity of Phenolic Phytochemicals from Various Cultivars of Plums." Food Chemistry 81 (3): 321-6.

[11] Naknean, P., and Meenune, M. 2011. "Characteristics and Antioxidant Activity of Palm Syrup Produced in Songkhla Province, Southern Thailand.” Asian Journal of Food and Agro-industry 4 (4): 204-12.

[12] Aeimsard, R., Thumthanaruk, B., Jumnongpon, R., and Lekhavat, S. 2015. "Effect of Drying on Total Phenolic Compounds, Antioxidant Activities and Physical Properties of Palm Sugar.” J. Food Sci. Agric. Technol. 1 (11): 126-30.

[13] Pätzold, R., and Brückner, H. 2005. "Mass Spectrometric Detection and Formation of D-Amino Acids in Processed Plant Saps, Syrups and Fruit Juice Concentrates.” J. Agric. Food Chem. 53 (25): 9722-9. 